\title{
Properties of Polyhexamethylene Guanidine (PHMG) Associated with Fatal Lung Injury in Korea
}

\author{
Dong-Uk Park ${ }^{1, *(\mathbb{D}}$, Jihoon Park ${ }^{2,3} \mathbb{C}^{\mathbb{C}}$, Kee Won Yang ${ }^{4}$, Ju-Hyun Park ${ }^{5}$, Jung-Hwan Kwon ${ }^{6}$ \\ and Han Bin Oh ${ }^{4, *}$ \\ 1 Department of Environmental Health, Korea National Open University, Seoul 03087, Korea \\ 2 Environmental Safety Group, Korea Institute of Science and Technology Europe Forschungsgesellschaft \\ mbH, 66123 Saarbrücken, Germany; jhabso@nate.com \\ 3 Institute of Health and Environment, Graduate School of Public Health, Seoul National University, \\ Seoul 08826, Korea \\ 4 Department of Chemistry, Sogang University, Seoul 04107, Korea; scr1109@gmail.com \\ 5 Department of Statistics, Dongguk University, Seoul 04620, Korea; juhyunp@gmail.com \\ 6 Division of Environmental Science and Ecological Engineering, Korea University, Seoul 02841, Korea; \\ junghwankwon@korea.ac.kr \\ * Correspondence: pdw545@gmail.com (D.-U.P.); hanbinoh@sogang.ac.kr (H.B.O.); \\ Tel.: +82-2-3668-4707 (D.-U.P.); +82-2-705-7959 (H.B.O.)
}

Received: 18 June 2020; Accepted: 18 July 2020; Published: 21 July 2020

check for updates

\begin{abstract}
The use of humidifier disinfectant (HD) has been determined to be associated with lung injuries (HDLI) in Korea. Although HD brands containing polyhexamethylene guanidine (PHMG) oligomers have been found to cause more HDLI compared to brands containing other disinfectants, the physicochemical properties of PHMG have been poorly defined. We aimed to quantify the PHMG dissolved in HD brands, characterize the number-average $\left(M_{n}\right)$ and weight-average $\left(M_{w}\right)$ molecular masses, and identify the polymerization degree of PHMG. Analysis of the PHMG oligomers was performed using a matrix-assisted laser desorption/ionization time-of-flight mass spectrometer (MALDI-TOF MS) operated in positive-ion reflectron mode. Eight brands of HD containing PHMG were identified. The PHMG concentrations in these brands ranged from 160 to $37,200 \mathrm{ppm}($ mean $=3100.9 \mathrm{ppm})$. Concentration was a significant variable among and within HD brands. The degree of PHMG oligomerization fell within the range of two to four. The averages of $M_{n}$ and $M_{w}$ were $517.2 \mathrm{~g} / \mathrm{mol}$ (range: $422-613 \mathrm{~g} / \mathrm{mol}$ ) and $537.3 \mathrm{~g} / \mathrm{mol}$ (range: 441.0-678.0 g/mol), respectively. Based on the average molecular weight and the degree of polymerization, the PHMG examined here could be regarded as oligomers, which may be associated with the highest proportion of HDLI being caused by PHMG.
\end{abstract}

Keywords: humidifier disinfectant-associated lung injury; PHMG; oligomer; molecular mass; polymerization

\section{Introduction}

Several types of chemicals were widely used as humidifier disinfectants (HD) in South Korea from 1994 until the end of 2011. The use of HD brands containing polyhexamethylene guanidine (PHMG), oligo (2-(2-ethoxy) ethoxyethyl guanidinium (PGH), and a mixture of chloromethylisothiazolinone (CMIT) and methylisothiazolinone (MIT) has been confirmed to be associated with lung injury, including interstitial pneumonitis and widespread lung fibrosis. Collectively, this has been named humidifier-disinfectant-associated lung injury (HDLI) [1-3]. Several studies have demonstrated that chemicals added to a humidifier's water tank as a disinfectant in order to suppress microbial growth have caused fatal HDLI in children, pregnant women, and even adults [1,3]. From May 2013 to date, 
the government has operated the Humidifier-Associated Lung Injury Investigation and Decision Committee (HLIIDC) to evaluate whether registered patients are clinically associated with HD use [4]. Among 221 HDLI patients clinically examined through two rounds of investigations conducted from July 2013 until April 2015, a total of 123 (55.7\%) used HD products containing PHMG [4]. Even though HD products containing PHMG were found to cause the highest number of HDLI compared to HD brands using other disinfectants, the physicochemical properties of PHMG as used in the HDs have been poorly defined.

PHMG is a family of polymers containing guanidine subunits (Figure 1) that has been proven to be highly biocidal for a range of microorganisms while showing low toxicity to humans [5-7]. It has been regarded as a safe alternative to common disinfectants such as formaldehyde, ethylene oxide, chlorine, hypochlorite solutions, iodine, alcohols, phenols, or other compounds, and has undergone widespread application in all areas of human life as a nontoxic disinfectant or additive [8-10]. Biocidal cationic polymers, including PHMG, have attracted considerable attention for their high antibacterial activity and low human toxicity.

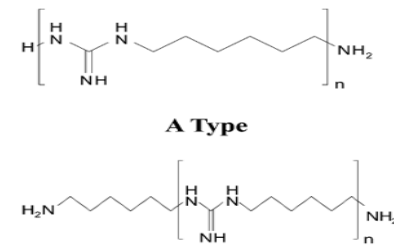

B Type

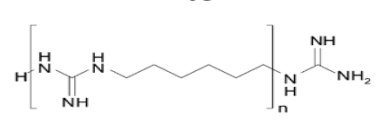

C Type

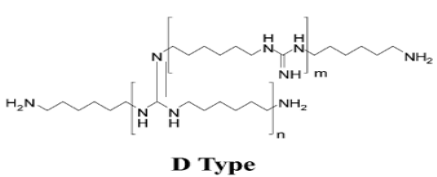

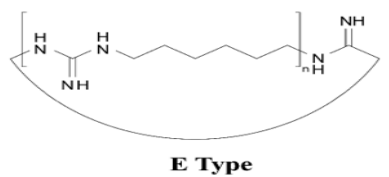
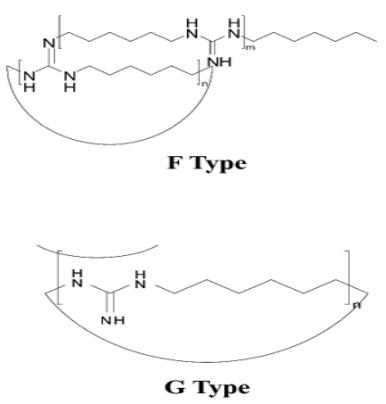

Figure 1. Structures of polyhexamethylene guanidine (PHMG) isomers. Depending on the polymer (oligomer) end groups and the connectivity between the two end groups, PHMG can take on different isomeric forms [11,12].

The objectives of this study are to quantify the concentrations of PHMG dissolved in HD brands and characterize the molecular weight and the degree of polymerization of PHMG. The results can be used to evaluate the effect of PHMG on the development of diseases, including lung injury.

\section{Results}

To date, a total of eight HD brands have been identified as containing PHMG. Oxy Saksak was manufactured as an HD from 2000 through the end of 2011, accounting for the majority of the market volume in Korea (Table 1). The sales volumes of other HD brands have not been identified, but would likely be minimal compared to Oxy Saksak. The concentrations of PHMG in HD brands ranged from 160 to $37,200 \mathrm{ppm}$ (mean $=3100.9 \mathrm{ppm}$ ). The concentration variation was significant both among and within HD brands, and also for products manufactured in different years within the same HD brand. However, specific trends within the PHMG concentration, year manufactured, and HD brand were not observed (Table 2 and Figure 2). Our results indicate that the degree of PHMG oligomerization was in the range of two to four. The averages of $M_{n}$ and $M_{w}$ were, respectively, found to be $517.2(\mathrm{~g} / \mathrm{mol})$, with a range of $422-613(\mathrm{~g} / \mathrm{mol})$; and $537.3(\mathrm{~g} / \mathrm{mol})$, with a range of $441.0-678.0(\mathrm{~g} / \mathrm{mol})$. The $M_{w}$ 's were slightly higher than $M_{n}$ 's (Table 3 and Figure 2). Based on the average molecular weight and degree of polymerization, the PHMGs examined here could be regarded as oligomers (Table 4). 
Table 1. Major brands of humidifier disinfectants containing PHMG.

\begin{tabular}{cccc}
\hline Brand Name & Sales Period & Total Sales Volume (mL/each) [13] & Cases of HDLI ${ }^{\mathbf{1}}$ \\
\hline Oxy Saksak (Old and New versions) & $2000-2011$ & $9,561,151$ of $500 \mathrm{~mL}$ & Yes \\
Lotte Wiselect & $2006-2011$ & 110,283 of $1000 \mathrm{~mL}$ & Yes \\
Homeplus & $2004-2011$ & 296,950 of $550 \mathrm{~mL}$ & Yes \\
Atorganic & $2009-2011$ & No information & Yes \\
Cefu & $2009-2011$ & No information & Yes \\
Vegetable Home Clean Up & $2009-2011$ & 106,943 of $1000 \mathrm{~mL}$ & No
\end{tabular}

1 The number of humidifier disinfectants associated with lung injury (HDLI) by the type of HD brand were reported elsewhere [4]. No HDLI cases were found among people who used other HD products not listed in this table.

Table 2. PHMG concentrations by the year of manufacture and type of humidifier brand.

\begin{tabular}{|c|c|c|c|c|c|}
\hline \multirow{2}{*}{ Brand Name } & \multirow{2}{*}{ Year } & \multirow{2}{*}{$\begin{array}{c}\text { Number of } \\
\text { Sample(s) }\end{array}$} & \multicolumn{3}{|c|}{ Concentration (ppm) } \\
\hline & & & Mean & SD & Range \\
\hline Cleanland & NI & 1 & 1500.0 & N/A & $\mathrm{N} / \mathrm{A}$ \\
\hline \multirow{10}{*}{$\begin{array}{c}\text { Oxy Saksak } \\
\text { New }\end{array}$} & 2004 & 3 & 3500.0 & 1479.9 & $2500-5200$ \\
\hline & 2005 & 7 & 2400.0 & 1724.3 & $900-5900$ \\
\hline & 2006 & 8 & 1431.3 & 820.1 & $670-3100$ \\
\hline & 2007 & 7 & 2382.9 & 1051.4 & $280-3500$ \\
\hline & 2008 & 4 & 1725.0 & 206.2 & $1500-2000$ \\
\hline & 2009 & 7 & 1914.3 & 803.0 & $1100-2800$ \\
\hline & 2010 & 14 & 2707.1 & 2025.0 & $1100-9000$ \\
\hline & 2011 & 14 & 1595.7 & 592.2 & $740-2600$ \\
\hline & NI & 15 & 1737.3 & 964.2 & $320-3900$ \\
\hline & Subtotal & 79 & 2051.0 & 1293.0 & 280-9000 \\
\hline \multirow{5}{*}{ Oxy } & 2001 & 1 & 2700.0 & $\mathrm{~N} / \mathrm{A}$ & N/A \\
\hline & 2002 & 1 & 3700.0 & N/A & N/A \\
\hline & 2003 & 1 & 3000.0 & $\mathrm{~N} / \mathrm{A}$ & $\mathrm{N} / \mathrm{A}$ \\
\hline & NI & 1 & 5000.0 & N/A & N/A \\
\hline & Subtotal & 4 & 3600.0 & 1023.1 & $2700-5000$ \\
\hline \multirow{4}{*}{$\begin{array}{c}\text { Vegetable } \\
\text { Home Clean } \\
\text { Up }\end{array}$} & 2009 & 1 & 160.0 & N/A & $\mathrm{N} / \mathrm{A}$ \\
\hline & 2010 & 3 & $12,600.0$ & 7607.9 & $4800-20,000$ \\
\hline & NI & 3 & $20,666.7$ & 5859.5 & $14,000-25,000$ \\
\hline & Subtotal & 7 & $14,280.0$ & 9261.4 & $160-25,000$ \\
\hline \multirow{3}{*}{ Cefu } & 2011 & 2 & $19,700.0$ & $24,748.7$ & $2200-37,200$ \\
\hline & NI & 1 & 1600.0 & - & 1600 \\
\hline & Subtotal & 3 & $13,666.7$ & $20,382.7$ & $1600-37,200$ \\
\hline Atorganic & NI & 1 & 560.0 & N/A & N/A \\
\hline \multirow{5}{*}{ Lotte Wiselect } & 2006 & 2 & 660.0 & 84.9 & $600-7200$ \\
\hline & 2008 & 1 & 690.0 & $\mathrm{~N} / \mathrm{A}$ & N/A \\
\hline & 2010 & 3 & 1146.7 & 185.8 & $940-1300$ \\
\hline & 2011 & 1 & 1500.0 & N/A & N/A \\
\hline & Subtotal & 7 & 992.9 & 345.9 & 600-1500 \\
\hline \multirow{4}{*}{ Homeplus } & 2009 & 1 & 1200.0 & $\mathrm{~N} / \mathrm{A}$ & N/A \\
\hline & 2011 & 6 & 1800.0 & 1143.7 & $1000-4000$ \\
\hline & NI & 1 & 2700.0 & N/A & N/A \\
\hline & Subtotal & 8 & 1837.5 & 1048.7 & $1000-4000$ \\
\hline \multicolumn{2}{|c|}{ Total } & 110 & 3100.9 & 5102.8 & $160-37,200$ \\
\hline
\end{tabular}

Abbreviations: SD, (arithmetic) standard deviation; N/A, not applicable; NI, no information. 

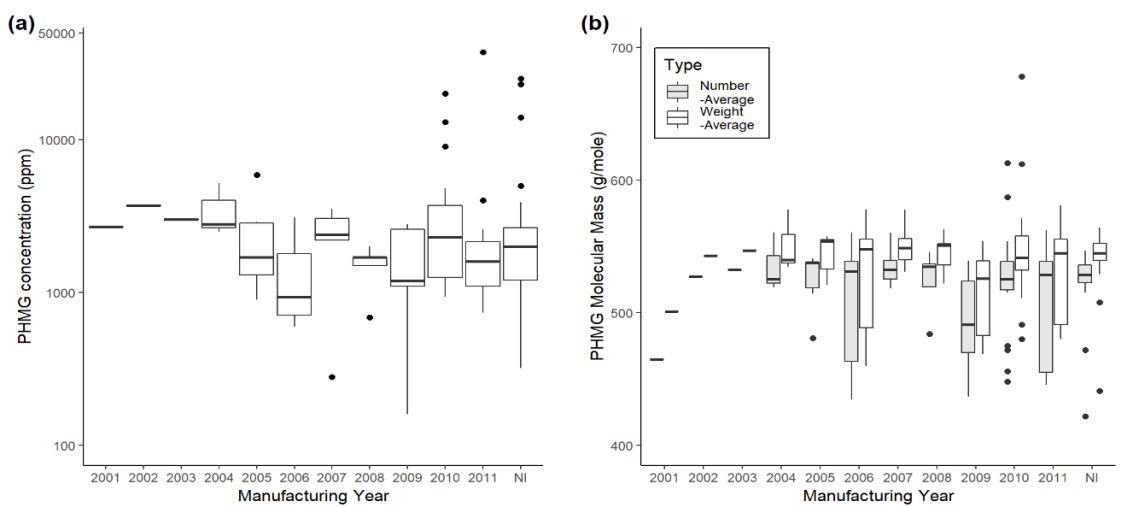

Figure 2. Boxplots of (a) PHMG concentration (ppm) on the log scale and (b) molecular mass (g/mol) contained in the humidifier disinfectant (HD) products by year manufactured. Note: NI indicates "no information".

Table 3. The numbers $\left(M_{n}\right)$ and weights $\left(M_{w}\right)$ of average molecular masses of PHMG by brand and year manufactured.

\begin{tabular}{|c|c|c|c|c|c|c|c|c|}
\hline \multirow{3}{*}{$\begin{array}{l}\text { Brand } \\
\text { Name }\end{array}$} & \multirow{3}{*}{ Year } & \multirow{3}{*}{$\begin{array}{l}\text { Number } \\
\text { of } \\
\text { Sample } \\
\text { (s) }\end{array}$} & \multicolumn{6}{|c|}{ Average Molecular Weight (g/mol) } \\
\hline & & & \multicolumn{3}{|c|}{ Number (Mn) } & \multicolumn{3}{|c|}{ Weight (Mw) } \\
\hline & & & Mean & SD & Range & Mean & SD & Range \\
\hline Cleanland & NI & 1 & 422.0 & - & 422.0 & 441.0 & - & 441.0 \\
\hline \multirow{10}{*}{$\begin{array}{c}\text { Oxy } \\
\text { Saksak } \\
\text { New }\end{array}$} & 2004 & 3 & 535.0 & 22.4 & $519.0-560.6$ & 551.0 & 23.5 & $535-578$ \\
\hline & 2005 & 7 & 524.8 & 21.7 & $481.0-541.1$ & 544.1 & 14.9 & $521-558$ \\
\hline & 2006 & 8 & 503.2 & 53.4 & $435.0-560.8$ & 523.4 & 48.7 & $460-578$ \\
\hline & 2007 & 7 & 534.4 & 14.3 & $518.5-560.3$ & 550.0 & 15.9 & $531-578$ \\
\hline & 2008 & 4 & 534.2 & 10.9 & $519.5-545.7$ & 550.5 & 11.1 & $536-563$ \\
\hline & 2009 & 7 & 501.9 & 37.4 & $437.0-539.0$ & 525.0 & 29.6 & $469-554$ \\
\hline & 2010 & 14 & 521.3 & 41.7 & $448.0-613.0$ & 545.1 & 45.9 & $480-678$ \\
\hline & 2011 & 14 & 510.3 & 46.1 & $448.0-562.2$ & 532.4 & 39.2 & $480-581$ \\
\hline & $\mathrm{NI}$ & 15 & 533.1 & 7.3 & $520.3-545.9$ & 549.5 & 7.8 & $537-564$ \\
\hline & Subtotal & 79 & 520.7 & 35.1 & $435.0-613.0$ & 540.6 & 32.5 & $460-678$ \\
\hline \multirow{5}{*}{ Oxy } & 2001 & 1 & 465.0 & N/A & N/A & 501.0 & N/A & N/A \\
\hline & 2002 & 1 & 527.4 & N/A & N/A & 543.0 & N/A & N/A \\
\hline & 2003 & 1 & 532.7 & N/A & N/A & 547.0 & N/A & N/A \\
\hline & NI & 1 & 531.7 & N/A & N/A & 546.0 & N/A & N/A \\
\hline & Subtotal & 4 & 514.2 & 32.9 & $465.0-532.7$ & 534.3 & 22.2 & $501-547$ \\
\hline \multirow{4}{*}{$\begin{array}{l}\text { Vegetable } \\
\text { Home } \\
\text { Clean Up }\end{array}$} & 2009 & 1 & 483.0 & N/A & N/A & 483.0 & N/A & $\mathrm{N} / \mathrm{A}$ \\
\hline & 2010 & 3 & 542.4 & 38.9 & $515.2-587.0$ & 562.7 & 43.7 & $529-612$ \\
\hline & NI & 3 & 516.7 & 1.4 & $515.4-518.3$ & 530.0 & 1.0 & $529-531$ \\
\hline & Subtotal & 7 & 522.9 & 31.3 & $483.0-587.0$ & 537.3 & 38.4 & $483-612$ \\
\hline \multirow{3}{*}{ Cefu } & 2011 & 2 & 516.0 & 2.5 & $514.2-517.7$ & 528.5 & 0.7 & $528-529$ \\
\hline & $\mathrm{NI}$ & 1 & 472.0 & N/A & N/A & 508.0 & N/A & N/A \\
\hline & Subtotal & 3 & 501.3 & 25.4 & $472.0-517.7$ & 521.7 & 11.8 & $508-529$ \\
\hline Atorganic & $\mathrm{NI}$ & 1 & 546.9 & N/A & N/A & 562.0 & N/A & N/A \\
\hline \multirow{5}{*}{$\begin{array}{c}\text { Lotte } \\
\text { Wiselect }\end{array}$} & 2006 & 2 & 531.4 & 7.1 & $526.4-536.5$ & 548.0 & 8.5 & $542-554$ \\
\hline & 2008 & 1 & 484.0 & N/A & N/A & 522.0 & N/A & N/A \\
\hline & 2010 & 3 & 517.5 & 39.1 & $475.0-551.9$ & 540.3 & 29.0 & $511-569$ \\
\hline & 2011 & 1 & 533.0 & N/A & N/A & 549.0 & N/A & N/A \\
\hline & Subtotal & 7 & 518.9 & 28.4 & $475.0-551.9$ & 541.1 & 19.5 & $511-569$ \\
\hline \multirow{4}{*}{ Homeplus } & 2009 & 1 & 444.0 & N/A & N/A & 475.0 & N/A & N/A \\
\hline & 2011 & 6 & 493.9 & 41.1 & $446.0-532.7$ & 522.0 & 28.4 & $484-549$ \\
\hline & $\mathrm{NI}$ & 1 & 527.0 & N/A & N/A & 542.0 & N/A & N/A \\
\hline & Subtotal & 8 & 491.8 & 41.4 & $444.0-532.7$ & 518.6 & 30.6 & $475-549$ \\
\hline \multicolumn{2}{|c|}{ Total } & 110 & 517.2 & 35.9 & $422.0-613.0$ & 537.3 & 32.7 & $441-678$ \\
\hline
\end{tabular}

Abbreviations: SD, (arithmetic) standard deviation; NI, no information; N/A, not applicable. 
Table 4. The levels of polymerization of PHMG by HD brand.

\begin{tabular}{|c|c|c|c|c|c|}
\hline Brand Name & Year & Number of Sample(s) & Mean & SD & Range \\
\hline Cleanland & $\mathrm{NI}$ & 1 & 2.05 & - & 2.05 \\
\hline \multirow{10}{*}{$\begin{array}{c}\text { Oxy Saksak } \\
\text { New }\end{array}$} & 2004 & 3 & 3.79 & 0.16 & $3.68-3.98$ \\
\hline & 2005 & 7 & 3.57 & 0.55 & $2.33-3.84$ \\
\hline & 2006 & 8 & 3.20 & 0.88 & $2.11-3.98$ \\
\hline & 2007 & 7 & 3.79 & 0.10 & $3.68-3.97$ \\
\hline & 2008 & 4 & 3.79 & 0.08 & $3.68-3.87$ \\
\hline & 2009 & 7 & 3.11 & 0.80 & $2.12-3.82$ \\
\hline & 2010 & 14 & 3.38 & 0.66 & $2.17-3.93$ \\
\hline & 2011 & 14 & 3.26 & 0.83 & $2.16-3.99$ \\
\hline & NI & 15 & 3.78 & 0.05 & $3.69-3.87$ \\
\hline & Subtotal & 79 & 3.48 & 0.63 & $2.11-3.99$ \\
\hline \multirow{5}{*}{ Oxy } & 2001 & 1 & 2.26 & N/A & $\mathrm{N} / \mathrm{A}$ \\
\hline & 2002 & 1 & 3.74 & N/A & N/A \\
\hline & 2003 & 1 & 3.78 & N/A & N/A \\
\hline & $\mathrm{NI}$ & 1 & 3.77 & N/A & N/A \\
\hline & Subtotal & 4 & 3.39 & 0.75 & $2.26-3.78$ \\
\hline \multirow{4}{*}{$\begin{array}{c}\text { Vegetable } \\
\text { Home Clean up }\end{array}$} & 2009 & 1 & 3.43 & N/A & N/A \\
\hline & 2010 & 3 & 3.02 & 0.57 & $2.55-3.65$ \\
\hline & NI & 3 & 3.66 & 0.01 & $3.66-3.68$ \\
\hline & Subtotal & 7 & 3.35 & 0.46 & $2.55-3.68$ \\
\hline \multirow{3}{*}{ Cefu } & 2011 & 2 & 3.66 & 0.02 & $3.65-3.67$ \\
\hline & NI & 1 & 2.29 & N/A & N/A \\
\hline & Subtotal & 3 & 3.20 & 0.79 & $2.29-3.67$ \\
\hline Atorganic & NI & 1 & 3.88 & N/A & N/A \\
\hline \multirow{5}{*}{ Lotte Wiselect } & 2006 & 2 & 3.77 & 0.05 & $3.73-3.80$ \\
\hline & 2008 & 1 & 2.35 & NA & NA \\
\hline & 2010 & 3 & 3.31 & 0.88 & $2.30-3.91$ \\
\hline & 2011 & 1 & 3.78 & NA & NA \\
\hline & Subtotal & 7 & 3.37 & 0.72 & $2.30-3.91$ \\
\hline \multirow{4}{*}{ Homeplus } & 2009 & 1 & 2.15 & NA & NA \\
\hline & 2011 & 6 & 2.99 & 0.85 & $2.16-3.78$ \\
\hline & NI & 1 & 3.74 & NA & NA \\
\hline & Subtotal & 8 & 2.98 & 0.83 & $2.15-3.78$ \\
\hline \multicolumn{2}{|c|}{ Total } & 110 & 3.41 & 0.66 & $2.05-3.99$ \\
\hline
\end{tabular}

Abbreviations: SD, (arithmetic) standard deviation; NI, no information; N/A, not applicable.

\section{Discussion}

We described the physicochemical properties of PHMG based on its concentration, molecular weight, and degree of polymerization (Tables 1-3). The PHMG analyzed in this study contained oligomer compounds of relatively low molecular weight $\left(M_{w}\right)$, containing up to four monomer units. In addition, a monomer of hexamethylenediamine (HMDA), which did not react during the PHMG polymerization reactions, was found to remain within the range of a significant quantity. According to the Korean Centers for Disease Control and Prevention (KCDC) report that the average size of HD aerosol dispersed into the air ranged from $30 \mathrm{~nm}$ to $80 \mathrm{~nm}$ in a $1500 \mathrm{~L}$ chamber using an ultrasonic humidifier and monitored by a scanning mobility particle sizer (SMPS) [14], most of the inhaled PHMG dose can likely easily penetrate into the alveoli region of the respiratory system, the target organ injured by HD [15]. Because of the complex properties of PHMG, other physicochemical properties, such as the molecular mass, degree of polymerization, and concentration of HMDA, may be related to 
the level of toxicity. We will discuss how these properties of PHMG might be associated with health problems, including HDLI.

Firstly, the PHMG concentrations dissolved in HD brands were found to be far higher than the minimal inhibition concentration (MIC) of PHMG (range: 0.78-25 ppm) determined by testing for good antimicrobial activity against several different microorganisms, including bacteria and fungi [16-18]. PHMG has been reported to kill methicillin-resistant Staphylococcus aureus and Escherichia coli at concentrations as low as 0.04 and $0.005 \%$ (w/v), respectively, within $1.5 \mathrm{~min}$ [19]. Choi et al. reported that PHMG exerts antifungal activity against various fungal strains in the range of $1.25-2.5 \mu \mathrm{g} / \mathrm{mL}$ (ppm) [20]. These results suggest that PHMG induces membrane depolarization, resulting in the loss of membrane functions and leading to cell death. Zhou et al. reported that the inactivation effect of PHMG had a dose, time, and inoculum concentration [21]. They found the MIC value of PHMG to be 4 ppm, the lowest concentration of this antimicrobial that totally inhibited macroscopically visible growth of the inoculum. This result showed that a low concentration of PHMG mainly damaged the outer membrane structure and that no significant damage to the intracellular structure was observed. In contrast, after exposure to a high concentration of PHMG, although the general morphological structure of the cells was retained, the integrity of the cell wall layer structure was destroyed (mostly through collapse) and obvious gaps could be seen in some cells [21]. If $20 \mathrm{~mL}$ of PHMG at a concentration of $3073 \mathrm{ppm}$ is injected into $2 \mathrm{~L}$ of humidifier water, the estimated level of PHMG in the humidifier would be $30.7 \mathrm{ppm}$. Most of the levels of PHMG estimated based on average PHMG use and frequency per day could be higher than the MIC reported elsewhere [19,21].

Secondly, there may be a possibility that the molecular mass of PHMG is related to health problems, including HDLI. The molecular weight of PHMG used for identifying MIC has been around 1000 Daltons (Da). However, the number and weight of the average molecular masses of PHMG in the HD samples investigated in the current research were $517.2 \mathrm{~g} / \mathrm{mol}\left(M_{n}\right)$ and $537.3 \mathrm{~g} / \mathrm{mol}\left(M_{w}\right)$ (Table 3 and Figure 2), respectively, far lower than those required for an efficient antimicrobial activity assay (up to $800 \mathrm{Da}$ ) [22]. Interestingly, the molecular masses among various HD brands were similar, despite the differences in concentrations between and within HD brands. Wei et al. reported that an aqueous solution of PHMG $\left(M_{w}=640\right)$ at a concentration as low as $1.0 \mathrm{ppm}$ exhibited an antibacterial rate above $90.0 \%$ [11]. At least a significant portion of the commercially available oligomeric PHMG seems to be in the form of an oligomer with a lower degree of polymerization, which could not be classified as a "polymer" under the regulatory framework [23,24]. To our knowledge, the effect of the molecular weight of PHMG on health risks has not been examined. In general, components with a molecular mass above $1000 \mathrm{Da}$ are known to be very unlikely to be absorbed by the gastrointestinal tract, and thus are not considered to present a toxicological risk. The value of $1000 \mathrm{Da}$ was chosen because it takes into account the effect of the shape of the molecule, which has an important influence on the likelihood of absorption of substances in the molecular mass range of 600-1000 Da. Below 600 Da most substances are absorbed, and the rate of absorption is determined by factors other than the size and shape of the molecule [25]. Albert et al. concluded that lower $M_{w}$ 's (800) result in a rapid decrease of activity [22]. When increasing the chain length of the diamine, the biocidal activity drops accordingly. Regarding the parameters that have an influence on biocidal activity, it can be shown that the $M_{w}$ of oligoguanides has to be in the range of 800-1300 Da. The weight percentage of oligomers with a molecular weight $<500$ must be less than 5\% in the USA and China and 2\% in Japan and Korea [24].

In 1997, PHMG was registered as an existing chemical without any evaluation of its inhalation toxicity under the Toxic Substances Control Law (TSCL) of Korea (enacted in 1991), because the usage of PHMG as a humidifier disinfectant was not clearly defined [26]. PHMG was also registered in Australia by a major supplier from Korea, with the announced use as a microbial additive in plastics, fabric softeners, paints, swimming pools, and paper, as well as for sanitation in food processing plants and cooling towers. It was registered as a polymer with a measured average molecular weight number $\left(M_{n}\right)$ and average molecular weight $\left(M_{w}\right)$ of 18,500 and $137,000 \mathrm{~g} / \mathrm{mol}$, respectively [27]. The reported $M_{n}$ and $M_{w}$ values are much greater than those characterized in this study. Although the method of 
molecular weight determination was not specified in the National Industrial Chemicals Notification and Assessment Scheme (NICNAS) report, it is likely that gel permeation chromatography (GPC) was used, because the supplier submitted GPC results in Korea. Because polystyrene-equivalent $M_{w}$ obtained by GPC includes greater uncertainties [28], the current result of a much lower average molecular weight should be given priority over those previously reported.

Thirdly, the level of PHMG oligomers and different $M_{w}$ values may be associated with toxicity, including antibacterial activities. Oligomers 3 and 7 have approximately the same antibacterial activity as benzalkonium chloride (BAC) [22]. Ionic interactions of PHMG with head groups of cell membranes were found to be dominant in the distribution of PHMG between solid-supported lipid membranes and water [29]. However, PHMG also accumulated in an example membrane with cationic head groups (1,2-dioleoyl-3-trimethylammonium-propane, DOTAP), implying that the positively charged guanidine group of PHMG may align with the cationic head of the DOTAP lipid, leading to membrane disruption and pore formation [29]. Although further investigation is needed, it is probable that PHMG may enter the cell and interact with intracellular components after adherence to the membrane. The prevailing model for PHMG activity holds that guanidine kills bacteria through bacterial membrane damage, and that the polymer does not interact with mammalian cell membranes. To our knowledge, there has been no study to test how the characteristics of the PHMG oligomers found in this study associate with antimicrobial activity, including the degree of cell membrane permeation. We cannot rule out the possibility that PHMG from HD aerosols was deposited in the lung airway and that the active ingredient PHMG permeated the epithelial barriers. This merits further studies on cell membrane permeability and related toxic mechanisms with the precise characterization of PHMG used in HDs. Further study is needed to evaluate whether differences between two counter ions of PHMG (phosphate and hydro chloride) are related to toxicity. No HDLI patient among the people who used only PHMG with hydrochloride has been reported to date, even though the concentrations used are far higher than those of PHMG-phosphate [30].

Finally, the level of hexamethylenediamine (HMDA) remaining unreacted as a monomer in HD brands may contribute to the development of HDLI. HMDA can cause irritation of the skin, eyes, and other mucous membranes in humans, as well as in the upper respiratory tract [31]. Park et al. estimated the airborne HMDA levels based on the dissolved concentration $(n=16$, range: 8.61 to 49.7 ppm, mean: $19.4 \mathrm{ppm}$ ) and HD use characteristics from five HD brands containing PHMG [13]. The levels of airborne HMDA ranged from 0.48 to $16.40 \mu \mathrm{g} / \mathrm{m}^{3}$, which were higher than the $1.8 \mu \mathrm{g} / \mathrm{m}^{3}$ value for respirable particles with diameters of $10 \mu \mathrm{m}$ and smaller [32]. Repeated exposure inhalation studies have defined the upper respiratory tract to be the first target of HMDA. The irritation seen is proportionate to the exposure concentration [31].

\section{Materials and Methods}

\subsection{Collection of Humidifier Disinfectant (HD) Samples}

All HD samples were collected from people who registered with the HLIIDC program during the environment investigation visit. Samples were stored in PE bottles, transported by ice box, and stored in a refrigerator. A total of 111 samples from HD brands that were assumed to contain PHMG were analyzed in order to characterize the physicochemical properties of the PHMG, such as the concentration, number-average $\left(M_{n}\right)$ and weight-average $\left(M_{w}\right)$ molecular masses, and the degree of polymerization. Samples with concentrations below the limit of quantitation (LOQ) for PHMG were excluded. The number of samples by HD brand were found to be severely unbalanced because of the considerable differences in sales volumes. The methods applied to evaluate the use characteristics of HDs based on personal interviews and home investigations have been described elsewhere [30,33]. Trained environmental health scientists visited registered patients' homes and conducted personal interviews and home investigations with the patients and their family members to complete detailed questionnaires or checklists related to HD use. 


\subsection{Quantification of PHMG}

Analysis of the PHMG oligomers was made using a matrix-assisted laser desorption/ionization time-of-flight mass spectrometer (MALDI-TOF MS, Autoflex series, Bruker Daltonics, Bremen, Germany) operated in the positive-ion reflectron mode. The experimental procedure is described in detail elsewhere [12,34,35]. Initially, qualitative analysis was performed to identify the presence of guanidine-containing oligomers. A sample was purified and enriched using mixed-mode solid-phase extraction (MCX SPE, $1 \mathrm{~mL}$, Waters; Milford, MA, USA). The MCX SPE cartridge consisted of a strong cation exchange and reversed-phase sorbent materials. The activation of the MCX cartridge was performed by eluting $1 \mathrm{~mL}$ of methanol (Fisher Scientific, Waltham, MA, USA) three times, and then pre-wetted by elution with $1 \mathrm{~mL}$ of a $0.1 \% \mathrm{HCl} /$ methanol solution $(\mathrm{pH}=2-3)$ three times; the $\mathrm{HCl}$ was purchased from Daejung (36.0-38.0\% w/w, Goryeong, Gyeongsangbuk-do Province, Korea). A sample was loaded by eluting $1 \mathrm{~mL}$ of the analyte solution through the solid-phase extraction (SPE) cartridge. This cartridge was washed by eluting $1 \mathrm{~mL}$ of $0.1 \% \mathrm{HCl} / \mathrm{methanol}$ solution three times. Finally, the guanidine-containing oligomers were eluted by $1 \mathrm{~mL}$ of a $2 \mathrm{M} \mathrm{HCl} / \mathrm{methanol}(\mathrm{pH}=1-2)$ solution. The eluted analyte solution was dried by nitrogen blowing at the $1 \mathrm{~mL}$ Eppendorf tube. Water of high-performance liquid chromatography (HPLC) grade (Burdick and Jackson, Morristown, NJ, USA) was added into the Eppendorf tube to produce a $1 \mathrm{~mL}$ final solution.

Through solid-phase extraction, other matrix materials could be eliminated and the guanidine-containing oligomers were selectively enriched. The purified sample was mixed with an ionic liquid matrix (ILM) composed of $\alpha$-Cyano-4-hydroxycinnamic acid (CHCA, CAS No. 28166-41-8, Sigma, St. Louis, MO, USA) and 1-methyl-imidazole (CAS No. 616-47-7, Sigma, St. Louis, MO, USA). A $1 \mu \mathrm{L}$ aliquot of the mixed ILM sample solution was deposited onto a MALDI plate, wherein a homogeneous thin film of the mixed material was formed. The homogeneous thin film ensured a reproducible detection of the analytes under examination. The MALDI mass spectra were acquired by irradiating a $355 \mathrm{~nm}$ laser light operating at $500 \mathrm{~Hz}$. Five different points within the single MALDI plate spot were sampled using 1000 laser shots to get a single MALDI mass spectrum. The acquired MALDI mass spectra were examined to see whether there are peaks corresponding to the $m / z$ values of the oligomer series and their isomers. The operation parameters for the MALDI-TOF MS were as follows: ion-source 1 voltage, $+19.05 \mathrm{kV}$; ion-source 2 voltage, $+16.70 \mathrm{kV}$; laser power percentage, $48 \%$; pulsed ion extraction, $140 \mathrm{~ns}$; lens voltage, $+8.24 \mathrm{kV}$; reflector voltage, $+20.99 \mathrm{kV}$; and reflector 2 voltage, $+9.73 \mathrm{kV}$.

Once the guanidine-containing oligomers were identified, quantitative analysis was made by comparing the abundance of the detected peaks with those of the corresponding internal isotope peaks. First, a calibration plot was constructed using the standard ${ }^{12} \mathrm{C}$ and reference (internal standard) ${ }^{13}$ C-labeled counterpart guanidine oligomers (FutureChem, Seoul, Korea). Then, 1000 ppm of the internal standard of the identified oligomer was spiked into the sample under investigation. Thus, the sample and the internal standard material were subjected to the same sample purification and quantitative measurement procedure to ensure accurate quantitation.

\subsection{Detection of the Guanidine Oligomers}

Figure 3 shows a representative MALDI-TOF mass spectrum for one of the Oxy Saksak HD brand samples spiked with the $1000 \mathrm{ppm}{ }^{13} \mathrm{C}$ PHMG internal standard. As clearly denoted with $\mathrm{A}_{l}, \mathrm{~B}_{m}$, and $C_{n}$ series oligomer isomers, the PHMG oligomers were identified (Figure 1). These isomers, which were made naturally through a synthetic procedure, have different oligomer end groups. Each series of the PHMG oligomers was found to have a 141 Da spacing between the neighboring series oligomers, for example, $\mathrm{A}_{3}(\mathrm{~m} / \mathrm{z} 441.4)$ and $\mathrm{A}_{4}(\mathrm{~m} / \mathrm{z}$ 582.5), consistent with the reported PHMG unit monomer mass value [35]. It is also notable that in the insert of Figure 2, the ${ }^{13} \mathrm{C}$ labeled internal standard peak (e.g., $C_{3}{ }^{*}$ ), appears with the $m / z$ gap of 4 Da from the counterpart PHMG oligomer isomer peak $C_{3}$; in each monomer unit, four carbons were labeled with ${ }^{13} \mathrm{C}$. By comparing the relative abundance ratios 
between the peaks unlabeled and labeled (e.g., $C_{3}$ and $C_{3}{ }^{*}$ ), the amount of the PHMG oligomers in the sample can be roughly estimated, which in this case is $1800 \mathrm{ppm}$.

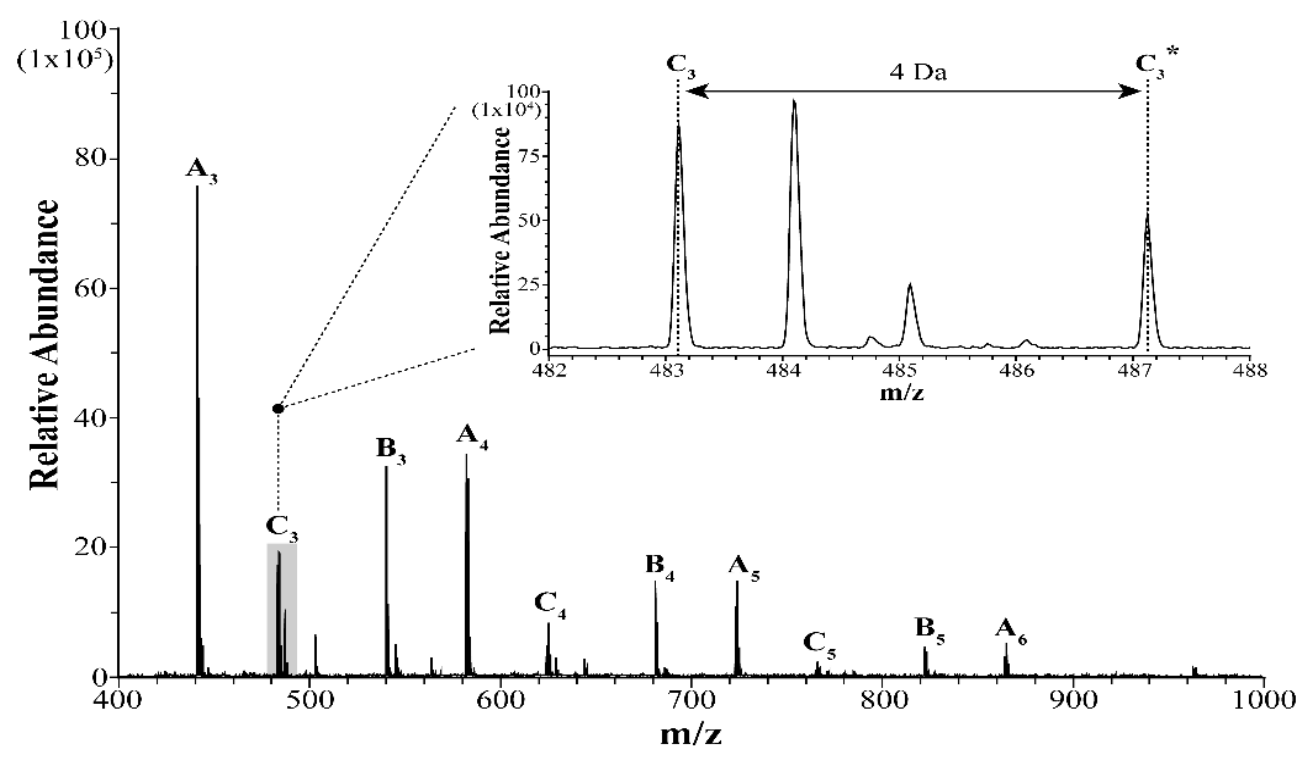

Figure 3. A representative matrix-assisted laser desorption/ionization time-of-flight mass spectrometer (MALDI-TOF MS) spectrum in the $\mathrm{m} / \mathrm{z}$ range of 400 to 1000 . PHMG oligomer peaks are labeled following the notation nomenclature shown in Figure 1. Inset: an enlarged mass spectrum showing a 4 Da spacing between the unlabeled $C_{3}$ and labeled internal standard $C_{3} *$ oligomer peaks.

\subsection{Calibration Curve}

A calibration curve was constructed for PHMG in the range of 50-10,000 ppm using six concentration points. The linearity of the calibration plot was satisfactory with a squared correlation coefficient $\left(R^{2}=0.9994\right)$ (Figure 4$)$. The precision determined by calculating the coefficient of variation $(\mathrm{CV}, \%)$ of replicates within runs on one day (intra-day) was well below $15 \%$ for a wide range of PHMG concentrations. The accuracy (relative error) obtained by calculating the percent deviation from the nominal concentration was mostly within $10 \%$ of the nominal values. The recovery efficiency was determined to be $73 \%$; some analytes were lost during the sample purification procedure.

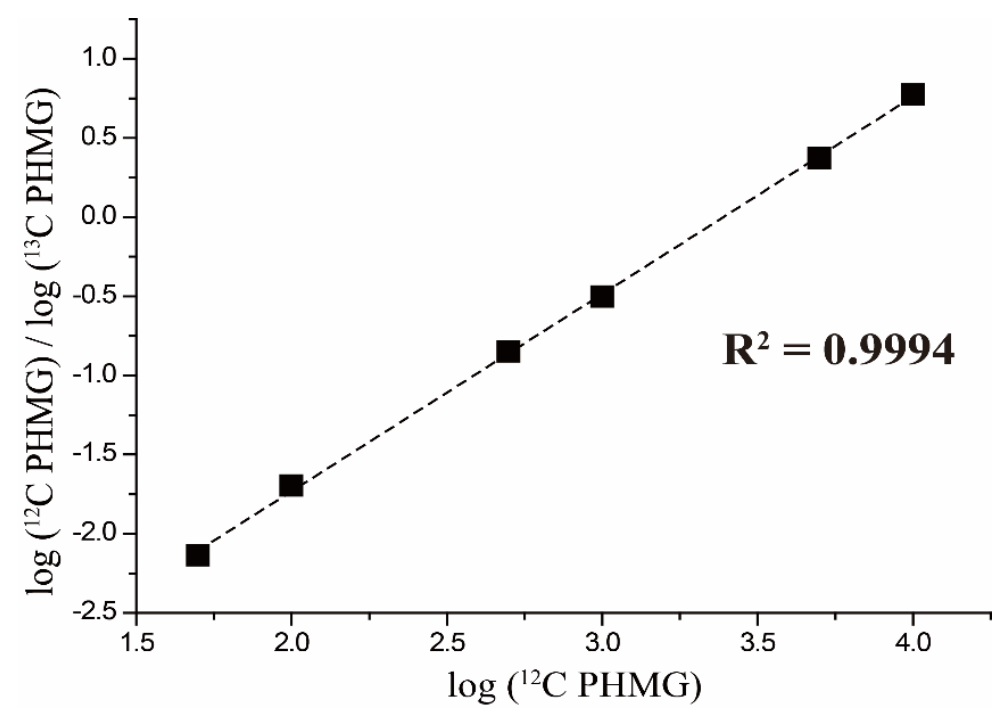

Figure 4. A calibration curve for PHMG in the range of 50-10,000 ppm. 


\subsection{Average Molecular Mass of PHMG}

The number-average $\left(M_{n}\right)$ and weight-average $\left(M_{w}\right)$ molecular masses (or weights) were determined using the following Equations (1) and (2) [36].

$$
\begin{gathered}
M_{n}=\sum_{i} N_{i} M_{i} / \sum_{i} N_{i} \\
M_{w}=\sum_{i} N_{i} M_{i}^{2} / \sum_{i} N_{i} M_{i}
\end{gathered}
$$

where $N_{i}$ and $M_{i}$ refer to the number (here, abundance) of individual molecule (or peaks) and the individual molecular weight, respectively. The number-average molecular masses (weights) observed for the samples under examination were in the range of 422.0-546.9, corresponding to the 3-4 mers of PHMG. Because larger oligomer (polymer) molecules in a sample weigh more than smaller molecules, $M_{w}$ should always have a higher value than $M_{n}$ (i.e., $M_{w}>M_{n}$ ).

\subsection{Degree of Polymerization of PHMG}

The degree of polymerization is the number of monomeric units in a polymer or oligomer. For the given polymer or oligomer, the number- or weight-average degree of polymerization can be calculated using the following Equation (3).

$$
\text { Degree of polymerization }=M_{n} \text { or } M_{w} / M_{o}
$$

where $M_{o}$ is the molecular weight of the monomer unit, which in this case is $141 \mathrm{~g} / \mathrm{mol}$.

\subsection{Data Analysis}

The physicochemical properties of PHMG, such as the concentration of PHMG dissolved in HD brands, molecular weight, and polymerization level, were shown along with the HD brand and year of manufacture. The samples with concentrations below the limit of quantitation (LOQ) were excluded. Descriptive analyses were performed using STATA 12.0 (STATA Corp, College Station, TX, USA) and R software (ver. 3.6.1, The R Foundation for Statistical Computing, Vienna, Austria).

\section{Conclusions}

This study found that the degree of PHMG oligomerization was in the range of two to four based on the average molecular weight and the degree of polymerization, and that the PHMGs used in the humidifier could be regarded as oligomers. Even though our results for the physicochemical properties of PHMG may not be representative of all HD brands containing PHMG, since HD brands vary by year of manufacture and type of HD brand, this study assumed that the highest proportion of HDLI caused by the PHMG in Korea may be related to several physicochemical properties, including high concentrations, low molecular weights with an oligomeric nature, and a low polymerization degree of PHMG. Further study is needed to examine how several physicochemical characteristics of PHMGs, including the molecular mass and level of HMDA, can be associated with HDLI.

Author Contributions: Conceptualization, formal analysis, writing—original draft preparation and supervision, D.-U.P.; software, writing-original draft preparation, visualization, J.P.; methodology, investigation, formal analysis, K.W.Y.; methodology, software, data curation and validation, J.-H.P.; conceptualization, data curation and validation, J.-H.K.; conceptualization, investigation, validation, writing-review and editing, H.B.O. All authors have read and agreed to the published version of the manuscript.

Funding: This work was supported by the Special Commission on Social Disaster Investigation (Grant No. 12198215600) and by the "Technology Program for Establishing Biocide Safety Management" funded by the Korea Ministry of Environment (Grant No.2018002490001).

Conflicts of Interest: The authors declare no conflict of interest. 


\section{References}

1. Yang, H.J.; Kim, H.J.; Yu, J.; Lee, E.; Jung, Y.H.; Kim, H.Y.; Seo, J.H.; Kwon, G.Y.; Park, J.H.; Gwack, J. Inhalation toxicity of humidifier disinfectants as a risk factor of children's interstitial lung disease in Korea: A case-control study. PLoS ONE 2013, 8, e64430. [CrossRef] [PubMed]

2. Kim, K.W.; Ahn, K.; Yang, H.J.; Lee, S.; Park, J.D.; Kim, W.K.; Kim, J.T.; Kim, H.H.; Rha, Y.H.; Park, Y.M. Humidifier disinfectant-associated children's interstitial lung disease. Am. J. Resp. Crit. Care Med. 2014, 189, 48-56. [CrossRef]

3. Kim, H.J.; Lee, M.S.; Hong, S.B.; Huh, J.W.; Do, K.H.; Jang, S.J.; Lim, C.M.; Chae, E.J.; Lee, H.; Jung, M. A cluster of lung injury cases associated with home humidifier use: An epidemiological investigation. Thorax 2014, 69, 703-708. [CrossRef] [PubMed]

4. Park, D.U.; Ryu, S.H.; Lim, H.K.; Kim, S.K.; Choi, Y.Y.; Ahn, J.J.; Lee, E.; Hong, S.B.; Do, K.H.; Cho, J.L. Types of household humidifier disinfectant and associated risk of lung injury (HDLI) in South Korea. Sci. Total Environ. 2017, 596, 53-60. [CrossRef]

5. Worley, S.; Sun, G. Biocidal polymers. Trends Polym. Sci. 1996, 11, 364-370.

6. Tashiro, T. Antibacterial and bacterium adsorbing macromolecules II Macromol. Mater. Eng. 2001, $286,63-87$.

7. Ascenzi, J.M. Handbook of Disinfectants and Antiseptics; CRC Press: Boca Raton, FL, USA, 1995.

8. Ohta, S.; Misawa, Y.; Miyamoto, H.; Makino, M.; Nagai, K.; Shiraishi, T.; Nakagawa, Y.; Yamato, S.; Tachikawa, E.; Zenda, H. A comparative study of characteristics of current-type and conventional-type cationic bactericides. Biol. Pharm. Bull. 2001, 24, 1093-1096. [CrossRef]

9. Messick, C.R.; Pendland, S.L.; Moshirfar, M.; Fiscella, R.G.; Losnedahl, K.J.; Schriever, C.A.; Schreckenberger, P.C. In-vitro activity of polyhexamethylene biguanide (PHMB) against fungal isolates associated with infective keratitis. J. Antimicrob. Chemother. 1999, 44, 297-298. [CrossRef] [PubMed]

10. Kim, B.; Anderson, J.; Mueller, S.; Gaines, W.; Kendall, A. Literature review-Efficacy of various disinfectants against Legionella in water systems. Water Res. 2002, 36, 4433-4444. [CrossRef]

11. Wei, D.; Ma, Q.; Guan, Y.; Hu, F.; Zheng, A.; Zhang, X.; Teng, Z.; Jiang, H. Structural characterization and antibacterial activity of oligoguanidine (polyhexamethylene guanidine hydrochloride). Mater. Sci. Eng. C 2009, 29, 1776-1780. [CrossRef]

12. Hwang, H.J.; Nam, J.; Yang, S.I.; Kwon, J.H.; Oh, H.B. MALDI-TOF analysis of polyhexamethylene guanidine (PHMG) oligomers used as a commercial antibacterial humidifier disinfectant. Bull. Korean Chem. Soc. 2013, 34, 1708-1714. [CrossRef]

13. Park, D.U. Analysis of Components of Disinfectant Contained in Humidifier Disinfectant Products; Special Commission on Social Disaster Investigation: Seoul, Korean, 2020. (In Korean)

14. Korean Centers for Disease Control \& Prevention (KCDC). Aerosolization of Humidifier Disinfectant; Public Health Weekly Report No. 45; Department of Epidemiology Research: Seoul, Korean, 2020; pp. 831-832. (In Korean)

15. Park, D.U.; Ryu, S.H.; Roh, H.S.; Lee, E.; Cho, H.J.; Yoon, J.; Lee, S.Y.; Cho, Y.A.; Do, K.H.; Hong, S.J. Association of high-level humidifier disinfectant exposure with lung injury in preschool children. Sci. Total Environ. 2018, 616, 855-862. [CrossRef] [PubMed]

16. Zhang, Y.; Jiang, J.; Chen, Y. Synthesis and antimicrobial activity of polymeric guanidine and biguanidine salts. Polymer 1999, 40, 6189-6198. [CrossRef]

17. Feiertag, P.; Albert, M.; Ecker-Eckhofen, E.M.; Hayn, G.; Hönig, H.; Oberwalder, H.W.; Saf, R.; Schmidt, A.; Schmidt, O.; Topchiev, D. Structural characterization of biocidal oligoguanidines. Macromol. Rapid Commun. 2003, 24, 567-570. [CrossRef]

18. Buxbaum, A.; Kratzer, C.; Graninger, W.; Georgopoulos, A. Antimicrobial and toxicological profile of the new biocide Akacid plus@. J. Antimicrob. Chemother. 2006, 58, 193-197. [CrossRef] [PubMed]

19. Müller, G.; Kramer, A. Effect of selected wound antiseptics on adult articular cartilage (bovine sesamoid bone) in the presence of Escherichia coli and Staphylococcus aureus. J. Orthop. Res. 2005, 23, 127-133. [CrossRef]

20. Choi, H.; Kim, K.J.; Lee, D.G. Antifungal activity of the cationic antimicrobial polymer-polyhexamethylene guanidine hydrochloride and its mode of action. Fungal Biol. 2017, 121, 53-60. [CrossRef]

21. Zhou, Z.; Wei, D.; Guan, Y.; Zheng, A.; Zhong, J. Damage of escherichia coli membrane by bactericidal agent polyhexamethylene guanidine hydrochloride: Micrographic evidences. J. Appl. Microbiol. 2010, 108, 898-907. [CrossRef] 
22. Albert, M.; Feiertag, P.; Hayn, G.; Saf, R.; Hönig, H. Structure-activity relationships of oligoguanidines influence of counterion, diamine, and average molecular weight on biocidal activities. Biomacromolecules 2003, 4, 1811-1817. [CrossRef]

23. European Chemicals Agency (ECHA). Committee for Risk Assessment RAC: Annex 1: Background Document to the Opinion Proposing Harmonised Classification and Labelling at Community Level of Ammoniumpentadecafluorooctanoate (APFO). Available online: https://echa.europa.eu/documents/10162/ d4685869-d34d-1078-5e5a-e6e92a2736f6 (accessed on 1 June 2020).

24. ChemSafetyPro. Comparison of Global Polymer Registration Requirements. Available online: https://www.chemsafetypro.com/Topics/Review/polymer_registration_in_EU_USA_China_Japan_ Korea_Taiwan_Philippines.html (accessed on 13 June 2020).

25. European Centre for Ecotoxicology and Toxicology of Chemicals (ECETOC). The ECETOC Conceptual Framework for Polymer Risk Assessment (CF4 Polymers). Available online: http://www.ecetoc.org/wpcontent/uploads/2019/06/ECETOC-TR133-1CF4Polymers.pdf (accessed on 1 June 2020).

26. Lee, J.H.; Kim, Y.H.; Kwon, J.H. Fatal misuse of humidifier disinfectants in Korea: Importance of screening risk assessment and implications for management of chemicals in consumer products. Environ. Sci. Technol. 2012, 46, 2498-2500. [CrossRef]

27. National Industrial Chemicals Notification and Assessment Scheme (NICAS). Polyhexamethyleneguanidine Phosphate. Available online: http://www.sudmed.ru/index.php?act=Attach\&type=post\&id=2882 (accessed on 1 June 2020).

28. East, G.; McIntyre, J.; Shao, J. Polybiguanides: Synthesis and characterization of polybiguanides containing hexamethylene groups. Polymer 1997, 38, 3973-3984. [CrossRef]

29. Ha, Y.; Kwon, J.H. Effects of lipid membrane composition on the distribution of biocidal guanidine oligomer with solid supported lipid membranes. RSC Adv. 2020, 10, 22343-22351. [CrossRef]

30. Park, D.U.; Friesen, M.C.; Roh, H.S.; Choi, Y.Y.; Ahn, J.J.; Lim, H.K.; Kim, S.K.; Koh, D.H.; Jung, H.J.; Lee, J.H. Estimating retrospective exposure of household humidifier disinfectants. Indoor Air 2015, 25, 631-640. [CrossRef]

31. Kennedy, G.L., Jr. Toxicity of Hexamethylenediamine (HMDA). Drug Chem. Toxicol. 2005, 28, 15-33. [CrossRef] [PubMed]

32. Myers, J.L.; Grant, R.L. Development of a chronic inhalation reference value for hexamethylenediamine using an exposure model based on the dihydrochloride salt. Inhal. Toxicol. 2015, 27, 440-449. [CrossRef] [PubMed]

33. Park, D.U.; Choi, Y.Y.; Ahn, J.J.; Lim, H.K.; Kim, S.K.; Roh, H.S.; Cheong, H.K.; Leem, J.H.; Koh, D.H.; Jung, H.J. Relationship between exposure to household humidifier disinfectants and risk of lung injury: A family-based study. PLoS ONE 2015, 10, e0124610. [CrossRef] [PubMed]

34. Yoon, D.; Lee, D.; Lee, J.H.; Cha, S.; Oh, H.B. Quantitative analysis of polyhexamethylene guanidine (PHMG) oligomers via matrix-assisted laser desorption/ionization time-of-flight mass spectrometry with an ionic-liquid matrix. Rapid Commun. Mass Sp. 2015, 29, 213-219. [CrossRef] [PubMed]

35. Bae, J.; Park, M.; Lee, J.; Song, I.; Ju, Y.; Lee, C.S.; Kwon, J.H.; Moon, B.; Oh, H.B. Quantitative MALDI-TOF mass spectrometric analysis of biocidal polyhexamethylene guanidine (PHMG) oligomers in consumer products. Int. J. Mass Spectrom. 2019, 435, 298-304. [CrossRef]

36. Nielen, M.W. MALDI time-of-flight mass spectrometry of synthetic polymers. Mass Spectrom. Rev. 1999, 18, 309-344. [CrossRef]

Sample Availability: Samples of the compounds are not available from the authors. 